\title{
Young and Evolving: A Narrative of Veterinary Educational Research from Early Leaders
}

\author{
Katherine Fogelberg, Julie Hunt, Sarah Baillie ${ }^{1}$ \\ Center for Innovation in Veterinary Education and Technology (CIVET), Lincoln Memorial University College of Veterinary Medicine, 6965 Cumberland Gap Parkway, \\ Harrogate, TN 37752, USA, 'Bristol Veterinary School, Langford, Bristol BS40 5DU, UK
}

\section{Abstract}

Narrative inquiry is a qualitative research approach that tells the story of lived experiences through the eyes of those who experienced it, as interpreted by the researcher(s). Veterinary educational research (VER) is a relatively new and emerging field with an increasing number of faculty champions spread around the world. The lived experiences of some of the faculties who were involved in VER from the early days and have produced a body of work contributing to the growth of the discipline tell a collective story that outlines the challenges and benefits of being trailblazers for a new field of inquiry. The specific challenges identified included lack of resources, a sense of isolation, lack of respect for the discipline, and having to acquire the skills and knowledge necessary for successful transition from a clinical to an education focus. Their individual narratives also provided an overall positive outlook on the field, from influencing school policies to better, more satisfying teaching and leadership roles and from the excitement of learning a new discipline to nurturing future veterinary education researchers; the participants were generally upbeat about the value their contributions have made and will continue to make. This study provides a narrative that weaves together the individual stories of these VER trailblazers, based on semistructured interviews conducted during 2020; it demonstrates the ongoing need to support those who choose to pursue VER, cultivate a culture in which veterinary medicine values such research, and begin training veterinarians to engage in it early in their careers.

Keywords: Narrative, qualitative research, veterinary education, veterinary educational research

\section{INTRODUCTION}

While medical education research is a well-established field of inquiry, veterinary educational research (VER) is an emerging area that is beginning to grow and evolve. As accreditation standards continued to develop and evolve at the turn of the 21 st century, with a greater emphasis on Day 1 competencies and preparing graduates for the workplace, there was a parallel need to adapt and modernize veterinary teaching, learning, and assessment..$^{[1-3]}$ An additional drive for VER has been the research requirement in accreditation standards that can partially be fulfilled by VER. The first bespoke journal dedicated to veterinary education, The Journal of Veterinary Medical Education, was launched in 1974. ${ }^{[4]}$ In the decades since its inception, the journal has continued to expand in length and has become more researchbased ${ }^{[4-6]}$ VER is now an emerging discipline in veterinary

\begin{tabular}{|l|l|}
\hline \multicolumn{2}{|c|}{ Access this article online } \\
\hline Quick Response Code: & Website: \\
\hline & www.ehpjournal.com \\
\hline & \\
\hline
\end{tabular}

schools worldwide, including those in low- and middleincome countries, that seek to improve the quality of their teaching.

However, educational research in professional training programs, such as nursing, medicine, and pharmacy, faces multiple challenges. These challenges include limited funding leading to a lack of evidence-based practices ${ }^{[7,8]}$; the push-pull of defining "good" educational research, which, because it involves human subjects rather than experimental pieces (as in bench science trials), necessitates some flexibility ${ }^{[9]}$; the lack of respect and support for

\section{Address for correspondence: Dr. Katherine Fogelberg, Center for Innovation in Veterinary Education and Technology (CIVET) Lincoln Memorial University College of Veterinary Medicine, 6965 Cumberland Gap Parkway, Harrogate, TN 37752, USA E-mail: Katherine.fogelberg@Imunet.edu}

This is an open access journal, and articles are distributed under the terms of the Creative Commons Attribution-NonCommercial-ShareAlike 4.0 License, which allows others to remix, tweak, and build upon the work non-commercially, as long as appropriate credit is given and the new creations are licensed under the identical terms.

For reprints contact: reprints@medknow.com

How to cite this article: Fogelberg K, Hunt J, Baillie S. Young and evolving: A narrative of veterinary educational research from early leaders. Educ Health Prof 2022;4:124-33.

Submission: 09.07.2021 Revision: 09.09.2021 Acceptance: 28.09.2021 Web Publication: 01.02.2022 
educational research ${ }^{[10]}$; and the lack of resources (human, money, time, references) to support those interested in engaging in such research. ${ }^{[7]}$

Another challenge for VER specifically is the lack of a centralized, easily accessible resource for those interested in engaging in VER, although there is a comparable resource for medical education research. ${ }^{[1]}$ Because educational research is very different from bench science research, those who wish to embark on a career in VER find it difficult to find, digest, and synthesize the necessary knowledge and skills because they are either so scarce (veterinary-specific) or so vast (research methods, education). As a result, several experienced veterinary educational researchers came together and were awarded a grant by the Council for International Veterinary Medical Education (CIVME) to create an open-access handbook on VER, which is currently being written and will be made available no later than June 2022.

As part of this project, the team performed a survey of those working in the field of VER and those who intend to participate in the future. ${ }^{[12]}$ The survey's aim was to determine what types of VER were being undertaken or planned as well as to investigate the barriers to working in VER, ways to overcome such challenges, and tips for success. ${ }^{[12]}$ The research team also engaged in semistructured interviews with six veterinary educational researchers identified as prolific contributors and early leaders in the field with the aim of understanding more about their journey into VER and experiences along the way.

\section{Approach to data}

Narrative as a research approach and method continues to evolve in both its definitions and its use. Abbott ${ }^{[13]}$ defines narrative as "the representation of an event or a series of events" (p. 12) in the third edition of his The Cambridge Introduction to Narrative book. Other terms used in conjunction with narrative and in reference to it as a research approach include narrative discourse, narrative inquiry, personal narrative, and institutional narrative. ${ }^{[13-15]}$ While these monikers and definitions are helpful guides to those using the methodology, it also reminds us that it is not necessary to strictly follow the interpretation of a single scholar or group of scholars with regard to the application of any qualitative research approach. This is partially because qualitative approaches in general are continually evolving, as noted earlier, thus allowing some license in their application.

The evolution in narrative inquiry specifically is explicitly addressed by Chase ${ }^{[15]}$ in her chapter titled "Narrative inquiry: Toward theoretical and methodological maturity" published in Denzin and Lincoln's most recent The Sage Handbook of Qualitative Research. In it, Chase covers the history and evolution of narrative inquiry, beginning with the narrow initial definition of narrative as focussed only on oral discourse that was temporally sequenced and retrospective $\mathrm{e}^{[16]}$ and tracing it through current times, where it has expanded to encompass all types of communication (verbal, written, images, and the like); coherent and non-coherent temporality, past, present, and future presentations of information; and the ways in which narrative research can change an individual, a group, and/ or an institution. ${ }^{[15]}$

As one of the goals of the original research team was to learn about and convey the narrative of VER as a burgeoning field, Connelly and Clandinin's ${ }^{[14]}$ use and definition of narrative inquiry is the best-albeit imperfect - fit for our approach for this study. "Narrative research is not simply the telling or recounting of stories; it involves the gathering of data, the interpretation of that data, and the retelling of participants' stories in light of the questions being addressed by the research study." We have chosen to analyze the narratives acquired through semi-structured interviews to find similarities among the participants and report those out as themes and subthemes here, which serve to convey our interpretation of the collective narratives, thus fulfilling the charge of our chosen definition of narrative research.

\section{Materials and Methods}

This study was approved by the Institutional Review Board at Lincoln Memorial University, number 915 V.0. Four female and two male participants were interviewed via Zoom video conferencing by a single author (XX) using an interview guide that asked questions about participants' journeys within the profession of veterinary medicine as educational researchers (Appendix 1). Interviews ranged in length from 43 to $88 \mathrm{~min}$ and were recorded and transcribed by Zoom's auto-transcription service. The interviewer did the initial cleaning of the transcripts, including removing timestamps and correcting inaccuracies in transcription.

The participants were selected based on the number of publications in veterinary and other educational journals and their assigned H-index. Participants had held or currently hold various leadership roles in veterinary programs spanning North America, the UK, and Continental Europe. All six interviewees had obtained clinical specialty training within veterinary medicine; three had obtained graduate degrees in education.

The researchers have a variety of backgrounds and experience as well. The interviewer (XX) has 9 years' experience teaching veterinary students and engaging in VER using both quantitative and qualitative methods; she holds a Master of Science by research through her VER work. The primary coder (YY) is a veterinarian with over a decade of small animal clinical practice experience and a terminal degree in education, where she was trained in and embraced the value of qualitative research methods. She 
has been working to improve teaching in higher education for most of her career. The secondary coder (ZZ) is a veterinarian with many years in clinical practice and educational research. She brings her combined knowledge and experience to the study.

Transcripts were analyzed for themes by two authors (YY, $\mathrm{ZZ}$ ), with the first conducting an in-depth analysis and the second providing an initial review. Based on the results of the free response survey data and the in-depth and initial analysis of the interviews, it was agreed that sufficient triangulation and saturation had been reached.

\section{Data analysis}

Using an inductive coding approach, the initial coder (YY) read through the interviews and made manual field notes consisting of potential emergent themes and the occasional word or phrase that was not quite clear or may have been mis-transcribed. After the first pass, YY went through Zoom's recording and reconciled any questions she had from the first pass; Zoom's transcription feature at times lost words or incorrectly transcribed during crucial thoughts. The next pass by YY was to update the codes based on corrected transcripts. The third pass was to verify all codes and begin to consolidate the large number of initial themes. The fourth pass looked at the theme consolidation and arrangement of subthemes, whereas the fifth and final pass resulted in four over-arching themes, each with three to four subthemes.

A second coder (ZZ) reviewed the data and provided preliminary themes. The second coder made a first pass through the data, making notes and identifying overarching themes. On the second pass, $\mathrm{ZZ}$ made notes about each individual theme and re-read the notes and transcripts to refine the themes. The two coders (YY, ZZ) met via Zoom to compare field notes and resultant themes, which were found to be similar. The ensuing discussion centered on further coalescing the themes and subthemes, as well as reviewing the narrative inquiry approach to the data.

\section{RESULTS}

Four themes, each with three or four subthemes, emerged from across the data: (1) a sense of personal responsibility (personal/professional sacrifice/cost; strengthening the profession through VER; commitment to lifelong learning; elevating the profile of education and education research); (2) building a community of practice $[(\mathrm{CoP})$; the value of conferences; interdisciplinary collaborations; build and nurture a personal $\mathrm{CoP}]$; (3) the role of veterinary academia in veterinary education (accidental educators learning through on the job training; institutions of one; role of administrators; veterinary profession is slow and difficult to change); and (4) the bad and the good (lack of resources; lack of respect for education research, especially qualitative research; overwhelming amount of data and topics; positive effects of VER efforts). Each theme, along with its subthemes, is further explored subsequently. Pseudonyms have been used to protect the identity of interviewees.

\section{Sense of personal responsibility}

All participants expressed a dual sense of personal responsibility to the profession of veterinary medicine and to the discipline of education. However, this commitment came at a personal and professional sacrifice, sometimes significant, for several of them. One of the more seasoned participants stated:

So you have to let some go, and I feel really sorry for people who are trying to do say education research and development around also still doing clinical work because I think that's really hard. Because you're having to keep yourself up to date and even develop your knowledge on the educational side. So you have to sort of cut yourself off from it and that's like cutting an arm or a leg off for somebody who's qualified as a vet really, because there's an identity thing as well, you know. This question of "Am I still a real vet?" is something you grapple with. Yeah, I mean, I'm fairly reconciled to that...but it's really hard (Evan, p. 9).

Another participant had to make a similar choice: "And after a few years, I thought I have to make a choice, because I cannot stay up to date in both disciplines, internal medicine and education" (Logan, p. 2).

Though there were some personal and professional sacrifices, there were also some wonderful opportunities to follow through on their commitment to lifelong learning, whether through pursuing a graduate degree in their second discipline of education, recognizing the real differences between benchtop/quantitative and educational/qualitative research methods, or realizing that they had so much to learn when it came to teaching, learning, and education research. Avery, for example, summed up the idea of natural science vs. education research nicely: "And to let go of all-yeah, that's a good tip - let go of all the knowledge we have about how to do research in natural science. Let go of that, and start in an open field, and see what happens" (p. 6).

At least one participant expressed regret at having missed the chance to do a second $\mathrm{PhD}$, this one in education:

...one of the things that I probably would have done if I hadn't gone into the administrative side with the succeeding role too early, I did play with the idea for a couple of years of doing another $\mathrm{PhD}$ in education...I did look into that and thought about 
it, and then just never did. But I kind of wish I had actually (Jordan, p. 13).

Jordan's statement conveys the idea that learning never ends while also making it clear that learning about education on the job is a much harder and longer road. Regardless of whether their learning was achieved on the job, through formal graduate training, or both, all the participants were aware of their responsibility to strengthen the veterinary profession through VER. For some, that meant helping faculty colleagues understand the value of VER and guiding them through the process, for those interested in learning more. For others, it meant cultivating the idea of VER as a viable career path for their veterinary students, even if ensuring those students realized from the start that VER is not for the uncommitted. Evan, for example, periodically meets with students who are interested in learning more about VER. However, Evan has learned over the years that sometimes those students think VER is an easy research path and attempts to relieve them of that notion:

[to students looking to do educational research] I say if you come to me because you think an education or professionalism project is easy, then go and find someone to do a 6 control rat, 6 test rat study with if you want an easy project, because these [education projects] are the hardest - or do a retrospective clinical project (Evan, p. 10).

While Evan focussed on cultivating VER interest in well-motivated students, Avery and Peyton have created opportunities to mentor faculty along the VER path. This is exciting, challenging, and has proven to be a fine balancing act:

With my colleagues, for instance at institution or at our university, when you become an assistant professor you have to take a pedagogical oneyear course and they have to do a project there. And now for the first time, I am the supervisor of one of those colleagues, [who] is really... is really interested and very good. So, I am trying to-though $[\mathrm{X}]$ is also a splendid surgeon so with my conscience, I can't take [X] away from surgery-but I will try to encourage [X] to keep doing educational projects (Avery, p. 5).

I have a lot of different collaborators within the College, and that's been very purposeful. So very often, it will be a colleague who will say, "I want to do something different in my anatomy course or something," and I will help them to do that. And that's a way of trying to always help my colleagues be thinking about how they could be involved in educational research (Peyton, p. 6).
Regardless of who the participants were mentoring, how much formal vs. experiential training they had, or how they felt about their work within VER, all the participants were fully committed to elevating the profile of education and educational research. They did this in various ways, whether it was through putting themselves out there and using their successes to draw others in, creating opportunities to showcase education as a discipline at their college, or simply being willing to talk with students and colleagues about their work in ways that helped them understand its value and why they should consider trying VER. As Avery put it: "I will say another output is spreading the news and trying to make other people find education interesting and wanting to do research" (p. 3).

\section{Building a CoP}

All of the participants emphasized the importance of building a CoP, although none used this precise phrase, which was first proposed by Lave and Wenger in 1991. ${ }^{[17]}$ Lave, an anthropologist, and Wenger, a computer scientist, theorized that learning is not an individual process but requires social interaction with others in their chosen field, who then help the collective group move toward full understanding of and participation in the sociocultural practices of the community. ${ }^{[17]}$

This concept was strongly identified by all the participants, generally beginning with their recognition of the value of conferences. Participants described first attending conferences, then networking with others outside the field of veterinary medicine, and finally presenting their work to help others understand the challenges unique to the profession. Through these processes, all the participants were able to build, become part of, and continue to grow their CoPs.

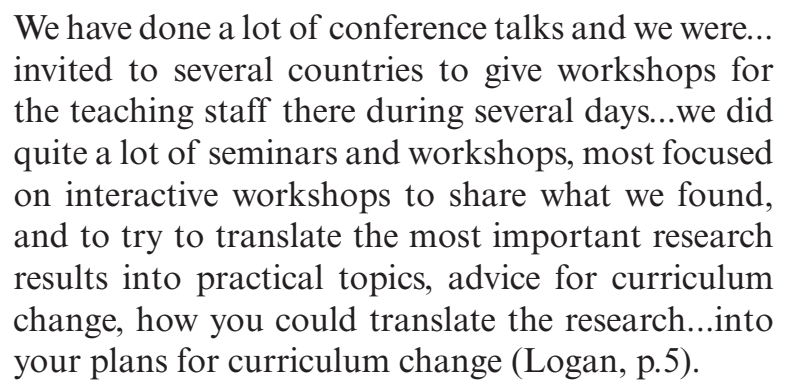

The importance of building interdisciplinary collaborations and nurturing their CoPs was emphasized as a big part of the participants' success; such collaborations contributed to their CoPs while also helping them learn the discipline of education and, more specifically, taught them the study designs and methods used to execute quality VER. "I [collaborated] with people from our medical school and I think that gave me a bit of a leg up rather than being just me going on my own. I was really looking for people that could give me a helping hand because I have no expertise in educational research" (Jordan, p. 2). 
These collaborations expanded beyond medical education and research; as the participants became more embedded in and confident in their work, they found many other disciplines willing to work with them and discovered the value of intentionally building teams that included members from other disciplines:

We...find...a lot of opportunities for collaboration across the disciplines now within the university; it's not just medical education, so we have a collaboration with [several disciplines outside medicine] on lecture recording, for example, and some of my other colleagues have collaborations on things like well-being and empathy across other areas of the university (Jordan, p. 4).

...team building in this part of the field is very important... We had different styles and different backgrounds...the $\mathrm{PhD}$ students...veterinarians and...educationalists and...a biologist. And especially the mix of educationalists...with veterinarians interested in veterinary educational research is, I would say is recommended, if you can find that, if you can develop that in... your team, the combination (Logan, p. 8-9).

Several participants noted a level of satisfaction induced by interdisciplinary work; they enjoyed the challenges of learning the language of other disciplines, as well as the opportunity to cross-pollinate their work. They also took specific pleasure in the dialogs with those who specialized in qualitative research:

I like working with people from other disciplines, I just welcome that. I like being exposed to them. It's sometimes a bit challenging understanding them, but I do feel that I'm fairly multilingual now across different academic disciplines, and so I can convert to the languages and ways of thinking and to pure qualitative researchers. And I love working with them (Evan, p. 11).

Jordan sums up the importance and value of CoPs nicely:

I would see collaboration as absolutely key...we're such a small discipline. You can't really do anything on your own, anyway, but I think it's even more the case in our field...it's about the expertise, the CPD [continuing professional development] type of opportunities, the path you decide to study in, and it's about the networks that you build through the collaborations (p. 10).

\section{Role of veterinary academia in veterinary education}

All our participants viewed themselves as accidental educators who learned through on-the-job training, though three did pursue formal graduate studies in education after they began teaching:
[I] came as a new faculty member...I taught in the clinics for 15 years, and in the classroom...So, a long history of classroom and clinical training, and at no point along that path did anybody provide any direction or support for teaching. It was...just something that you learn to do over time. And that was not ideal, not ideal” (Jamie, p. 1).

Learning to teach without outside support or guidance was a strong theme throughout and resonates with the existing literature on teacher training for those in higher education in general, especially within the sciences. ${ }^{[18]}$ To make matters even more complex, however, the participants also had to learn how to create and execute VER, a part of education that is rarely modeled and even more rarely taught. This is illustrated well by Logan: "When I started with educational research, I was a veterinarian. So I was a... kind of [an] autodidact into educational research, but I had no [formal] education [training]" (p. 4).

This is a clear endorsement of this group of VER scholars' commitment to lifelong learning as well.

While every participant committed to an academic career, they also recognized that their paths had been different from what they anticipated, and lonelier because of their dedication to VER rather than a strictly clinical career path. Although over time they all built their CoPs, they also all started as institutions of one:

"..the challenge was, of course, that I was, let's say, a lonely person...quite a lonely person in the first years... And of course, the Dean supported it and some people supported it, but I was the only one who got to go to the other professors. And at that time I was not a professor, so I was...in the lower hierarchical position. So that was a big challenge for me... later on I did not have challenges, but the first years I did because it was such a lonely position (Logan, p. 8).

This sense of isolation was not just lack of colleagues doing the same work or having interest in the processes; loneliness also arose from colleagues not appreciating their work:

I remember one professor...said to me, "I don't know why you're bothering with all these newfangled techniques in assessment...I just need to have a student in oral exam sitting in front of me for 10 seconds, and I can decide whether they're fit to practice or not." Now this is somebody who would not have dreamed of saying anything so absurd about their academic area... but they were a type of academic that seemed to have these blind spots around customs and practice in teaching and assessment and just didn't recognize that their 
arguments were facile really and indefensible (Evan, p. 3).

The role of administrators also played a part in the success and frustrations of the participants. While some were supportive to the point of paying for a graduate degree in education, others engaged in stifling VER:

Well, it's cumbersome work. You know, there's usually, traditionally, a lot of data involved. Sometimes it was hard to get [data] as department head. The associate dean wouldn't release some information, and so early on I had trouble getting data from the associate dean... I'm a department head. You don't trust me with, you know, student data. And he finally acquiesced. I offered to make him an author, he didn't want to be an author. And part of it was, he was troubled by the basis of the work which was maybe our admissions criteria don't actually predict how they [students] are going to do. That part was hard (Jamie, p. 5).

This follows the narrative that the veterinary profession is slow and difficult to change, though hope was expressed by some:

I think the viability of the profession depends on strengthening the educational process. And it's, you know, it's hard to change. It's a slow-moving ship or a strong train to turn around. It's highly steeped in tradition and going through the snow uphill both ways...it's hard. It was hard for me, it should be hard for them (Jamie, p. 7).

So I think I've seen a kind of move, a change in the discipline, actually, in terms of people's rating of qualitative research, definitely move to a more positive place now than I think it was when I first started with all this (Jordan, p. 3).

\section{The bad and the good}

There is a shortage of resources for research, regardless of the focus. However, in VER this is especially true. The lack of resources, particularly time and funding, was a consistent theme throughout the participants' narratives. Logan reflects positively on successes, while still being very clear that money was always an issue: "A lot of challenges [were] about money. Often still...I'm a little bit surprised that I managed to finance... [graduate] students while there was only limited budget" (p. 6). While this appeared to be a struggle universal to our participants, Peyton also had a positive view of the challenge:

...you know educational research projects generally are inexpensive. So even if you get them funded it's $\$ 3,000$ instead of half a million dollars, and so people just automatically see it as being less value, whereas I see it as being a tremendous value because I generated a ton of information. That's of an enormous benefit to everyone...versus needing to buy a piece of equipment that costs $\$ 300,000$. That's my view on the matter, though, not anyone else's view (p. 9).

The lack of resources available for VER is connected with another subtheme that there is a general lack of respect for education research, especially qualitative research; this idea emerged strongly across all participants. The lack of respect was frustrating, particularly when colleagues expressed narrow-minded views of research:

I have certainly had colleagues who were doing something very cool in a class that I approached and said, "hey, I hear you're doing this wonderful new thing. Let's gather some baseline data and then... we can compare these things and I'll help you do it. And I can even help write your IRB." ...[A]nd still, to some of those faculty there's just no value in doing that work because they just don't perceive that it will help them long term in their career. And...some of the schools I go to...it's just very clear educational research is not research. It's some sort of fun thing to do, like maybe when you're getting ready to retire. It's not real. And that's very difficult for me to hear because I think it just shows a lack of understanding of what educational research is (Peyton, p.10).

I guess the big lesson I have learned when I'm developing people as educators, and I'm thinking of basic scientists and clinical sort of vets here, but the same is true of educational research...you have to really ensure they understand that education is evidence based and should be evidence based. And qualitative methods collect a type of knowledge which is distinct from quantitative methods in various ways. But that doesn't mean it's not valuable. And that doesn't mean that it isn't true in the sense that any research is ever true as such. And explaining to them why qualitative methods are meaningful and should be taken seriously and are really the only way to make progress in so many areas of human experience" (Evan, p. 17-8; emphasis original).

Participants are well aware that many bench and clinical science researchers are averse to qualitative research, but they have opened their eyes to what such approaches can contribute and, as a result, continue to fight for its place in the literature. For example, Jordan sees qualitative research as having great potential:

...over time...I've got more and more enthused and excited by the potential for the qualitative methodologies... And almost fighting that corner 
against the more traditional scientists who might say well that's all the soft fluffy stuff and it's not generalizable and all of that (p. 3).

Avery recognizes the challenges that others have understanding qualitative research. Although a wellpublished qualitative researcher, Avery is still working to learn enough about qualitative research methods to be comfortable creating and executing such studies:

...using qualitative research methods...is still a challenge because it is really difficult to do well, and I still don't feel that I have enough knowledge about it. Now I have a sense of what to do, and I enjoy it, and it seems to work, but I still have that feeling that I could have done much better if I had known more about it (p. 4).

On the bright side of VER, all the participants took great delight in the overwhelming amount of available data and topics to study. A few participants found this a bit daunting, whereas others were amazed that there was so much available and so few willing or able to study it; others were excited about the vast openness of the field. Jamie stated this clearly:

...I became department head... and it really seemed unusual to me at that time that there are, you know, whole classrooms of students, tens of thousands of students walking into classrooms college classrooms every single day. And there was...a lot of opinion, but there was not a lot of data driven advice for what worked best (p. 2).

Avery came to this revelation early, after stating what seemed to be an obvious conclusion based on teaching experience; however, a colleague challenged Avery to provide evidence to support the observation:

...what I found interesting when I saw the students working with the models was that they became less nervous and I thought "well that's obvious, of course they do." And then somebody said "well you have to prove that" (p. 1).

Ultimately, our participants felt strongly that their work and careers had been worth the struggles; these positive effects of VER efforts manifested primarily in their pride in influencing students, whether directly or indirectly: "most of our projects do end up with 'and then we changed how we did radiology, then we changed how we teach embryology"' (Peyton, p. 15).

But I'm the most proud of the research in... professional or personal development of the students. When I started my work there was nothing of this kind in the curriculum, only veterinary topics. And I always found that's very important to get this in the curriculum and I'm so happy that one of the PhD students...did the research ...it was an important topic among all those research topics, especially important in the development of the curriculum (Logan, p. 3).

Every participant had both specific and general stories to share about how their VER contributions had helped effect positive change, whether at a local level at their specific school or across the profession. The participants were humble about their contributions and hesitant to acknowledge the impacts their work had beyond their classrooms or program, but it was clear throughout the data that every participant had positively impacted the profession. These impacts included mentoring students, evidence-based changes to curricula, and improving students' well-being during veterinary school, which in turn carries a positive influence throughout their careers beyond the classroom.

\section{Discussion}

These six in-depth interviews with recognized VER scholars who were early leaders in the field illuminate the challenges and opportunities presented by pursuing a veterinary career in education and, specifically, as an educational researcher. Some themes and subthemes that emerged were similar to those arising from this team's international survey of those performing and intending to perform VER, including the lack of funding available for educational research and the value of collaboration. ${ }^{[12]}$

While funding is a frequent limiting factor for all types of research, VER can often be completed with smaller budgets. Considering the cost of VER, the impact can be significant and timely; the findings have the potential to affect hundreds of students very quickly. Establishing sources of funding for VER will be critical to further advancement of the field. In medical education research, an association has been found between funding over $\$ 20,000$ and study quality. ${ }^{[19]}$

The participants' narratives and the survey data ${ }^{[12]}$ both emphasized the importance of collaboration. The collaborations described by participants can be considered building a CoP, or a social interaction with others in a single field of interest, which helps the entire group move toward full proficiency in the sociocultural practices of that community. ${ }^{[17]}$ The interviewees described starting by attending conferences with sessions focussed on teaching and learning or educational research. Expanding to education-focussed conferences and becoming a presenter, while simultaneously cultivating veterinary and interdisciplinary collaborations, can expand one's expertise and CoP. ${ }^{[20]}$ 
Beyond that, these vanguards became successful early leaders in a new field of inquiry by recognizing the importance and impact of pursuing formal training in education or by engaging in lifelong learning and by reconsidering the idea of being a veterinarian as strictly being in the clinical realm. Three of the six interviewees completed graduate training in education, whereas the others commented on considering it, wishing that they had, or describing how difficult their path of only experiential training was.

To continue to advance the field of VER, it is imperative to increase the number of academics pursuing professional development in education. Ideally, this would occur through graduate programs, with the financial support and time protections needed to ensure successful completion. Two graduate degree programs that focus specifically on veterinary education as a discipline exist: one is fully online and one offers the choice of either a fully online or hybrid program. A wide variety of traditional and online programs are also available in medical education ${ }^{[21]}$ and general education. While this represents an initial investment from the administration's perspective, it is likely to pay dividends in the long term through increased effectiveness in the classroom, increased scholarship in veterinary education, and trained faculty and staff who can mentor others. Other approaches to advancing the field might include creating a recognized specialty college for veterinary educators; increasing the number of veterinary education-specific teaching publications, handbooks, and textbooks; and providing more focussed training for veterinary students, interns, and residents to encourage early engagement with the field.

Our participants had different perspectives on the challenges of committing to VER rather than continuing in their clinical specialty, or on a bench or clinical science research path; for one it was an identity crisis - "Am I still a real vet?"-whereas for others it brought frustration, resignation, or even loneliness. In the end, however, all the participants were proud of the work they have done and continue to do and were fully committed to mentoring veterinary students and professionals in VER. They have all made positive impacts within the profession, and all were hopeful that VER would continue to grow and be more supported and recognized as valuable to the profession.

\section{Conclusion}

This study dives deeply into the individual lived experiences of six well-established veterinary educational researchers and presents an aggregated narrative that provides a remarkable illustration of challenge and triumph, both personal and professional, of those who chose to embark on a career in VER. In providing this profile of the trailblazers in the field, we celebrate their impact on the veterinary profession by exposing their sacrifices and successes to shed light on the importance of VER and encourage others to embrace, support, and pursue this path.

The participants in this study make a compelling case that more needs to be done to support VER and those who choose to pursue it, including cultivating a culture where veterinary medicine as a profession values such research and offering training for veterinarians to do VER early in their careers. Growing the CoP that provides mentorship and modeling of VER creates additional opportunities for recognition of this work. While challenges in VER exist, the field remains wide open to veterinarians and educators who are looking for an exciting opportunity to do something non-clinical, while still influencing clinical veterinary medicine.

\section{Financial support and sponsorship}

Nil.

\section{Conflicts of interest}

There are no conflicts of interest.

\section{RefEREnCES}

1. Royal College of Veterinary Surgeons. Veterinary education and training: A framework for 2010 and beyond. A consultation paper prepared by the RCVS Education Steering Group [Internet]. London, UK; 2001. Available from: https://www.rcvs.org.uk/ document-library/essg-consultation-document-2001/. [Last accessed on $2021 \mathrm{Jul} 8$ ].

2. Lloyd JW. Developing a curriculum to improve the skills, knowledge, aptitudes, and attitudes of veterinary students. J Am Vet Med Assoc 2002;220:976-7.

3. Molgaard L, Hodgson J, Bok H, Chaney K, Ilkiw J, et al.; American Association of Veterinary Medical Colleges Working Group on Competency-Based Veterinary Education. Competency-Based Veterinary Education: Part 1 - CBVE Framework. Washington, DC: Association of American Veterinary Medical Colleges; 2018.

4. Fletcher OJ, Hooper BE, Schoenfeld-Tacher R. History of the journal of veterinary medical education. J Vet Med Educ 2015;42:501-4.

5. Olson L. Content analysis of a stratified random selection of JVME articles: 1974-2004. J Vet Med Educ 2011;38:42-51.

6. Schoenfeld-Tacher R, Alpi K. A 45-year retrospective content analysis of JVME articles. J Vet Med Educ 2021. doi: 10.3138/ jvme-2020-0073.

7. Gruppen LD, Durning SJ. Needles and haystacks: Finding funding for medical education research. Acad Med 2016;91:480-4.

8. Ahmed R, Farooq A, Storie D, Hartling L, Oswald A. Building capacity for education research among clinical educators in the health professions: A BEME (best evidence medical education) systematic review of the outcomes of interventions: BEME guide no. 34. Med Teach 2016;38:123-36.

9. Feuer M, Towne L, Shavelson R. Scientific culture and educational research. Educ Res 2002;31:4-14.

10. Root Kustritz MV, Nault AJ. Measuring productivity and impact of veterinary education-related research at the institutional and individual levels using the H-index. J Vet Med Educ 2020;47:414-20.

11. Cleland J, Durning S. Researching Medical Education. Hoboken, NJ: Wiley; 2015.

12. Baillie S, Hunt J, Ruohoniemi M, Phillips V, Thompson M, Aumarm W, et al. Academics' experiences in veterinary educational research: Results of an international survey. J Vet Med Educ, in press. 
Fogelberg, et al.: A narrative of VER

13. Abbott HP. The Cambridge Introduction to Narrative. 3rd ed. New York, NY: Cambridge University Press; 2021.

14. Connelly F, Clandinin D. Stories of experience and narrative inquiry. Am Educ Res Assoc 1990;19:2-14.

15. Chase SE. Narrative inquiry: Toward theoretical and methodological maturity. In: Denzin NK, Lincoln YS, editors. The Sage Handbook of Qualitative Research. 5th ed. Thousand Oaks, CA: Sage Publication, Inc.; 2018.

16. Labov W, Waletsky J. Narrative analysis: Oral versions of personal experience. J Narra Life Hist 1997;7:3-38. doi: 10.1075/ jnlh.7.02nar

17. Lave J, Wenger E. Situated Learning: Legitimate Peripheral Participation. New York, NY: Cambridge University Press; 1991.
18. Fogelberg K. Attitudes and beliefs of university science professors toward the discipline of education [Internet] 2014. Available from: https://repository.tcu.edu/handle/116099117/7163. [Last accessed on $2021 \mathrm{Jul} 8]$.

19. Reed DA, Cook DA, Beckman TJ, Levine RB, Kern DE, Wright SM. Association between funding and quality of published medical education research. J Am Med Assoc 2007;298:1002-9.

20. Baillie S, Rhind S, MacKay J, Murray L, Mossop L. The VetEd conference: Evolution of an educational community of practice. J Vet Med Educ 2021. doi: 10.3138/jvme-2020-0154.

21. Tekian A, Harris I. Preparing health professions education leaders worldwide: A description of masters-level programs. Med Teach 2012;34:52-8 
Fogelberg, et al.: A narrative of VER

\section{ApPEndix 1}

\section{Semi-structured interview questions}

Overview of project: (to be explained to interviewees in email and at the start of interview).

We are undertaking a project "Capacity building in veterinary educational research by developing an open access resource to support community members" supported by the Council on International Veterinary Medical Education (CIVME) who are part of AAVMC.

The output from the project will be the development of an open access handbook to support those undertaking veterinary educational research with the ultimate aims of helping to build capacity and enable the community to grow. The handbook is likely to include several sections covering the research process from start to finish, types of educational research methods, tips for success as well as overcoming the challenges.

We are conducting a semi-structured interview with you as you have been involved in veterinary educational research for a number of years and have a significant portfolio of publications. We would like to hear about your journey into educational research and about your experiences along the way.

\section{Questions}

1. Please describe your background:

- Name, institution, role

- Could you briefly describe your career? Including:

- How did you become involved in veterinary education?

- How did you become involved in veterinary educational research?

2. Please describe your work in, and outputs from, educational research, e.g.

- Areas (topics) of your research work within veterinary education (e.g., graduate outputs, simulator development, and validation);

- Types of projects (e.g., quantitative, qualitative, empirical studies, systematic reviews, etc.);

- Collaborations, e.g., led by you, you supervising others (DVM or PhD students, faculty, etc.), collaborative and if so "how," e.g., within your institution, beyond your institution nationally and/or internationally, with others outside of veterinary education, etc.;

- Outputs (e.g., publications, resources, validated simulator, influence policy, etc.) and who were the beneficiaries of these outputs (e.g., students, universities, etc.). 3a. Could you describe any challenges you have encountered during your career (specifically as an educational researcher/when undertaking educational research), e.g.

- For you personally:

- When you started

- And/or at other stages in your career

- Ones that have persisted throughout your career?

- Specific challenges related to:

- Certain study types

- Certain situations, e.g.

- Working with those new to research, e.g., supervising researcher students, faculty with no prior experience of educational research, e.g., clinical or purely teaching background

- Teams, international, etc.

- Other - can you think of any others

3b. For challenges that are mentioned: specifically how did you overcome each of these challenges?

4. What have you particularly enjoyed about doing educational research?

Prompts, e.g.

- At different stages: at the start, on the journey, now looking back after years of doing educational research

- A favorite project, type of research study, or topic?

5. What tips would you pass on to others who would like to build a successful career that includes veterinary educational research?

Prompts, e.g.

- How to get started (doing the first study, how, what, with whom, etc.)?

- Balancing with other work demands, etc.

- What top tips do you have for a successful outcome, e.g.

- Completing the study

- Getting published

- Other/s?

- Other

6. Have you come across any resources that you would particularly recommend to people starting veterinary educational research projects?

7. Do you have any other comments or points you would like to raise about educational research?

Thank you for participating in the interview. 